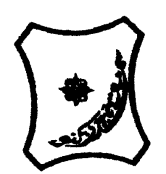

Bayero Journal of Pure and Applied Sciences, 8(2): 196 - 201

Received: June, 2015

Accepted: September, 2015

ISSN $2006-6996$

\title{
COMPARISON OF ANTIMICROBIAL ACTIVITY OF SEED OIL OF GARLIC AND MORINGA OLEIFERA AGAINST SOME FOOD-BORNE MICROORGANISMS
}

\author{
Abdulrasheed, M., Ibrahim, I.H., Mubarak, M.A. and Umar, F.A. \\ 1,2,3,Department of Microbiology, Gombe State University, P.M.B. 127 Gombe, Nigeria. \\ ${ }^{4}$ Abubakar Tafawa Balewa University, Bauchi State, Nigeria \\ Correspondence: moladeji@yahoo.com +2348039747494
}

\begin{abstract}
This study was aimed at evaluating the phytochemical constituents and the antimicrobial activity of the seed oil of Moringa oleifera and garlic against some selected food-borne microorganisms (Staphylococcus aureus, Escherichia coli, Salmonella spp and Pseudomonas aeruginosa) using disc diffusion method. The results of the phytochemical screening revealed differences in the presence of the phytochemicals among the extracts. Saponins were detected in both Moringa oleifera and garlic seed oil, while alkaloid and tannins were observed in seed oil of garlic. Furthermore, the antibacterial assay results shows that the seed oil of Moringa oleifera was inactive against all the tested organisms, even at $100 \%$ concentration. In contrast, garlic oil was found to be active against all the tested organisms. The highest inhibition was observed in E. coli $(12 \mathrm{~mm})$ at $100 \%$ concentration, while at $20 \%$ concentration, Salmonella Sp and P. aeruginosa showed resistance $(00 \mathrm{~mm})$. The antimicrobial activity of the seed oil of garlic may be attributed to its phytochemicals components which were not detected in the seed oil of Moringa oleifera. The results of this study have shown the potentials of the seed oil of garlic as an antimicrobial agent more especially in foods, by inhibiting the growth of the test organisms, which range from food-borne pathogens to food spoilage organisms. Keywords: Antimicrobial, garlic, Moringa oleifera, and food borne pathogens
\end{abstract}

\section{INTRODUCTION}

Antimicrobial agents are essentially important in reducing the global burden of infectious diseases. However, as resistant pathogens develop and spread, the effectiveness of the antibiotics is diminished. This type of bacterial resistance to the antimicrobial agents poses a very serious threat to public health, and for all kinds of antibiotics, including the major last-resort drugs, the frequencies of resistance are increasing worldwide. Therefore, alternative antimicrobial strategies are urgently needed, and thus this situation has led to a re-evaluation of the therapeutic use of ancient remedies, such as plants and plant-based products (Kingston, 2008). Medicinal plant is any plant in which one or more of its parts contains substance (phytochemical) that can be used for therapeutic purpose or which are precursors for the synthesis of useful drugs. About $80 \%$ of the world medicines are originally derived from plants sources especially those found in tropical regions. Phytochemicals are bioactive chemicals of plant origin. They are thus regarded as secondary metabolites because the plants that manufacture them may have little need for them. They are naturally synthesized in all parts of the plant body; bark, leaves, stem, root, flower, fruits, seeds, etc. Phytochemicals have been recognized as the basis for traditional herbal medicine practiced in the past and currently in vogue in parts of the world (Solomon. et al., 2013). In additon, medicinal plants have been identified and used throughout human history. Plants have the ability to synthesize a wide variety of chemical compounds that are used to perform important biological functions. Recently, considerable attention has been paid to eco-friendly and bio-friendly plants, which can prevent and cure different human diseases (Dubey et al., 2004). World Health Organization reported that the use of traditional medicine in the first world countries is on the rise due to failure of conventional medicine that can cure chronic diseases, emergence of multi-drug resistant pathogens and parasites, adverse effects of chemical drugs, increasing cost and information of herbal medicine. Antimicrobial potentiality of different medicinal plants is extensively studied all over the world (Ahmed et al., 1998). However, only a few studies have been carried out in a systematic manner. Moringa oleifera is a medicinal plant species, belonging to monogeneric family Moringaceae (order Brassicales). Almost all the parts of this plant: root, bark, gum, leaf, pods, flowers, seeds and seeds oil have been used for the various ailments in the indigenous medicine (Odebiyi and Sofowora, 1999). It is also known for it anti-helminthic activity, antimicrobial activity, detoxifier, immune booster and anti parasitic activity (Thilza et al., 2010), among others. Moringa oleifera is an important food commodity which has had enormous attention as the 'natural nutrition of the tropics'. 
Bajopas Volume 8 Number 2 December, 2015

The leaves, fruit, flowers and immature pods of this tree are used as a highly nutritive vegetable in many countries, particularly in India, Pakistan, Philippines, Hawaii and many parts of Africa (Anwar and Bhanger, 2003; Anwar et al., 2005). Moringa leaves have been reported to be a rich source of $\beta$-carotene, protein, vitamin $C$, calcium and potassium and act as a good source of natural antioxidants; and thus enhance the shelf-life of fat containing foods due to the presence of various types of antioxidant compounds such as ascorbic acid, flavonoids, phenolics and carotenoids (Dillard and German, 2000; Siddhuraju and Becker, 2003).

Garlic (Allium sativum L.) is among the oldest cultivated plant which is used for therapeutic purposes. Garlic has played one of the most important dietary and medicinal roles in human bodies for centuries and is used as a spice as well as medicinal herb. There are over 300 varities of garlic grown world wide. In addition to the well known garlic and numerous other species are extensively grown for cooking purpose, such as leek (Allium porrum L.), scallion (Allium fistulosum L.), and Chinese chive (Allium tuberosum L.) (Nuutila et al., 2002). The biological and medicinal functions of members of Alliaceae family are mainly due to their high organosulphur compound contents. It also contains many other sulfur containing compounds such as allin, ajoene, diallysulfide, dithin, Sallylcysteine, and enzymes, vitamin B, proteins, minerals, saponins, flavanoids, and mallard reaction products, which are non-sulfur containing compounds(Kojuri et al., 2007).

The plant which is of great medicinal importance takes place inside many foods especially meat ones due to its sharp odour, appetizer property and its calorie value is 140 , has $63.8 \mathrm{~g}$ water, $28.2 \mathrm{~g}$ carbohydrade, $5.3 \mathrm{~g}$ protein, $0.2 \mathrm{~g}$ oil and $11 \mathrm{~g}$ cellulose in it $100 \mathrm{~g}$ (Baytop, 1999). Garlic can be consumed as fresh and has also its pills, capsules and extracts. While it is safe, when taken in careful amounts, it can lacerate stomach, when consumed in excessive amounts(Ayaz and Alpsoy, 2007). There is a wide range of reported therapeutic effects, such as hypolipidaemic, antiatherosclerotic, hypoglycaemic, anticoagulant, antihypertensive, antimicrobial, antidote (heavy metal poisoning) and hepatoprotective, preventing cold and flu symptoms through immune enhancement and exhibit anticancer and chemopreventive activities (Amagase, 2006). The antimicrobial of crushed garlic have been known for a long time. A wide range of effects antimicrobial properties including antimicrobial activity has been reported for crushed garlic (Bakri and Douglas, 2005). Recent chemical characterisation of sulphur compounds has shown that they are the main active antimicrobial agents (Rose et al., 2005). Therefore, keeping in view the importance of these plants as important medicinal foods, this reseach was therefore, aimed at evaluating the phytochemical constituents and the antimicrobial activity of seed oils of garlic and Moringa oleifera against some food-borne microorganisms.

\section{MATERIALS AND METHODS}

\section{(a) Collection of the plants oil}

Factory extracted seed oils of Moringa oleifera and garlic with Batch no. 0034, B001, Manufacture date; 23/02/2013, 02/08/2013, and Expire date; 22/02/2016 and 01/08/2016 respectively were purchased from herbalist in Gombe main market, and were authenticated by a botanist at the Biological Sacience Department, Gombe State University.

\section{(b) Sample processing}

Strains of Escherichia coli, Staphylococcus aureus, Pseudomonas aeruginosa, and Salmonella Sp., Previously isolated from dried sliced beef (Kilishi), at the Microbiology laboratory of Gombe State University, were collected and inoculated onto freshly prepared Eosin Methylene Blue Agar (EMBA), Mannitol Salt Agar (MSA), Cystine Lactose Electrolyte Deficient Agar (CLEDA) and Salmonella Shigella Agar (SSA) respectively. And were then incubated at $35^{\circ} \mathrm{C}-37^{\circ} \mathrm{C}$ for 24hours (Greenwood, 2002). Plates with hundred or more were regarded as significant growth. Colonies with different morpological characteristics were subcultured onto freshly prepared nutrient agar plates, and incubated aerobically at $37{ }^{\circ} \mathrm{C}$ for 24 hours to obtain pure form (Cheesbrough, 2006). All the media were prepared according to manufacturers instruction. Isolated strains were Gram stained and then subjected to biochemical test which include; coagulase, catalase test, motility test, Lysine decarboxylase(LDC), Indole, urease, oxidase, citrase testand kligler iron agar (KIA) test, as described by Cheesbrough (2006), for confirmation.

\section{(c) Phytochemical Screening}

Phytochemical analysis for qualitative detection of alkaloids, flavonoids, tannins and saponins was performed on each of the oils, as described (Solomon et al., 2013).

\section{(i) Test for Alkaloids (Wagner's reagent)}

$1 \mathrm{ml}$ of each of the oils in separate tubes was treated with 3-5 drops of Wagner's reagent. Formation of reddish brown precipitate (or colouration) indicates the presence of alkaloids.

\section{(ii) Test for Flavonoids (Alkaline reagent test)}

$1 \mathrm{ml}$ of each of the oils in separate tubes was treated with few drops of $20 \%$ sodium hydroxide solution, and observed for the formation of intense yellow colouration, which becomes colourless on addition of dilute hydrochloric acid, indicates the presence of flavonoids.

(iii) Test for Saponins (Foam test). About $3 \mathrm{ml}$ of water was added to $1 \mathrm{ml}$ of each of the oils in separate tubes and shaked vigorously, formation of persistent foam, confirms the presence of saponins.

\section{(iv) Test for Tannins (Braymer's test)}

$1 \mathrm{ml}$ of each of the oils in separate tubes was treated with $10 \%$ alcoholic ferric chloride solution and observed for the formation of blue or greenish coloured solution.

\section{e) Standardization of Inoculum}

The inocula were prepared from stock cultures, which were maintained on nutrient agar slant at $4^{\circ} \mathrm{C}$ and subcultured onto nutrient broth using a sterilized wire loop. 
The density of suspension inoculated onto the nutrient broth was determined by comparison with 0.5 McFarland standard of barium sulphate solution (Cheesbrough, 2006).

\section{(f) Antimicrobial susceptibility test}

Mueller Hinton agar was prepared and sterilized as instructed by the manufacturer, the medium was poured into different petri dishes and allowed to cool. Using sterile swab sticks, each of the isolates was streaked across different plates. The inoculated plates were then allowed to stay for about 3-5 minutes. Prepared discs of the four different concentrations; 20 $\%(\mathrm{v} / \mathrm{v}), 40 \%(\mathrm{v} / \mathrm{v}), 60 \%(\mathrm{v} / \mathrm{v})$ and $100 \%$ of each of the oils were placed on the organism inoculated plates, with each of the plates containing different concentrations of one type of oil. Gentamicin $(10 \mu \mathrm{g})$ (Rapid labs, UK) was used as positive control while discs impregnated with DMSO was used as the negative control. Within 30 minutes of discs application, the plates were incubated aerobically in an inverted position at $37{ }^{\circ} \mathrm{C}$ for 24 hours. The diameter of the zone of inhibition was measured to the nearest millimeter ( $\mathrm{mm}$ ) using a milimeter rule, as modified by Kirby-Bauer technique (Cheesbrough, 2006). For each test organism, two replicates were performed.

\section{RESULT AND DISCUSSION}

Table I: Shows the phytochemical screening of seed oil of Moringa oleifera and Garlic. The result revealed the presence of alkaloid, saponins, and tannins in seed oil of Garlic. Whereas only saponins were detected in seed oil of Moringa oleifera.

Table II: Shows the efficacy of various concentratons of the seed oil of Moringa oleifera and Garlic against the bacterial isolates. The result indicated that seed oil of Moringa oleifera was inactive against the tested organisms, even at $100 \%(\mathrm{v} / \mathrm{v})$ concentration. In contrast, Garlic oil was active against all the tested microorganisms. The result further revealed that the higher the concentration of the seed oil of garlic, the higher its efficacy. Highest sensitivity was observed at $100 \%(\mathrm{v} / \mathrm{v})$ concentration and the least at $20 \%(\mathrm{v} / \mathrm{v})$ concentration.

Table I: Shows the phytochemical characteristics of seed oil of Moringa oleifera and Garlic

\begin{tabular}{lcc}
\hline Phytochemicals & M. Oleifera oil & Garlic oil \\
\hline Alkaloids & -- & + \\
Flavonoids & -- & -- \\
Saponins & + & + \\
Tannins & -- & + \\
\hline Key: $+=$ Present & &
\end{tabular}

Key: + = Present, -- = Absent.

Table II: Shows the antibacterial activity of seed oil of Moringa oleifera and Garlic

\begin{tabular}{lccccc}
\hline & \multicolumn{5}{c}{ Zone of Inhibition (mm) } \\
Oil sample & Conc. $\%(\mathbf{V} / \mathbf{V})$ & STA & EC & SS & PA \\
\hline M. oleifera oil & 20 & 0 & 0 & 0 & 0 \\
& 40 & 0 & 0 & 0 & 0 \\
& 60 & 0 & 0 & 0 & 0 \\
& 80 & 0 & 0 & 0 & 0 \\
& 100 & 0 & 0 & 0 & 0 \\
$+\mathrm{V}$ & 28 & 28 & 27 & 23 \\
\hline
\end{tabular}

$\begin{array}{cccccc}\text { Garlic oil } & 20 & 07 & 07 & 00 & 00 \\ & 40 & 08 & 08 & 07 & 07 \\ 60 & 08 & 09 & 08 & 07 \\ 80 & 09 & 09 & 09 & 08 \\ 100 & 11 & 12 & 11 & 10 \\ & +\mathrm{V} & 28 & 29 & 26 & 24\end{array}$

Key: STA = Staphylococcus aureus, EC = Escherichia coli, SS = Salmonella $s p, \mathrm{PA}=$ Pseudomonas aeruginosa $+\mathrm{v}=$ Positive control (Gentamicin) $---=$ No inhibition. 


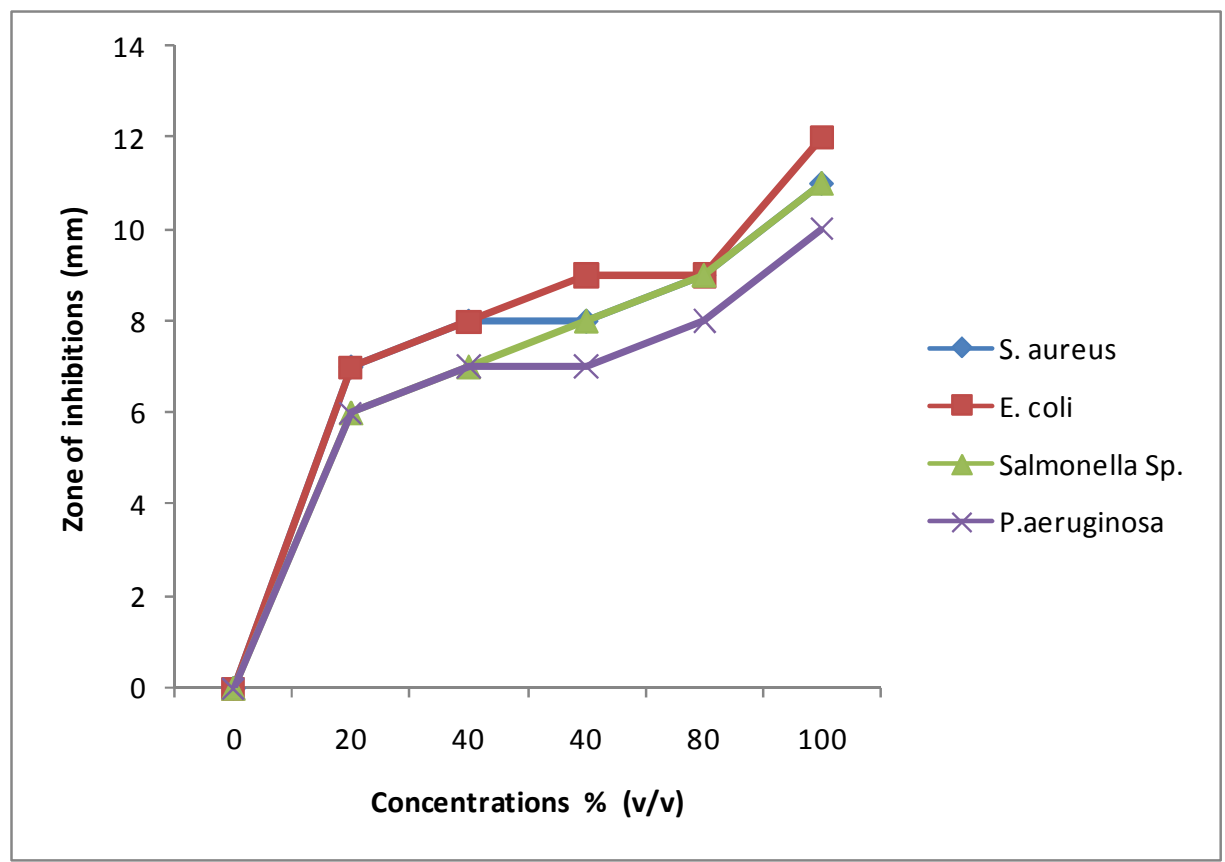

Fig. 1 Antimicrobial activity of seed oil of Garlic against E.coli, S. aureus, Salmonella Sp. and Pseudomonas aeruginosa.

This research was aimed at evaluating the phytochemical constituents and the antimicrobial activity of seed oils of garlic and Moringa oleifera against some food-borne microorganisms. Phytochemical screening of the seed oil of Moringa oleifera and Garlic revealed the presence of saponins,alkaloids, and tannins in Galic oil, whereas, only saponins were observed in seed oil of Moringa oleifera. This result is in accordance with the work carried out by Bukar et al.(2010) on antimicrobial profile of moringa oleifera lam extracts against some food-borne microorganisms, which shows the absence of alkaloids, flavonoids, and tannins in $M$. oleifera seed chloroform extract, only saponins were detected. Similarly, active constituents like, alkaloid, saponins, and tannins with exception of flavonoids were detected in garlic oil. Intresetingly, the findings in this work is in agreement with the work of Muhammad et al. (2014), who reported that tannins and alkaloids were present in garlic seed extract. But in contrast to this research, flavonoids was reported to be present in the garlic seed extract. However, saponins were observed in garlic oil in this work, which was not reported by Muhammad et al. (2014). Furthermore, Farooq et al. (2007) reported that plants occur in varying habitats, and a great magnitude of variation in the concentration and composition of phytochemical ingredients in the different parts of such plant is expected. In addition, Waller and Nowacki (1978), reported that phytochemicals are produced in response to perceived threats by the plants, as such variation exist in the production of these phytochemicals depending on the type and amount of threat encountered by the plant.

The antibacterial activity of various concentrations of the seed oil of Moringa oleifera and Garlic against the food-borne bacterial isolates, revealed that the seed oil of Moringa oleifera was inactive against all tested organisms, even at $100 \%(\mathrm{v} / \mathrm{v})$ concentration. This findings is in accordance with the work carried out by Spiliotis et al. (1997), on the antimicrobial activity of water seed extracts and seed oil of three Moringa oleifera varities, tested against various microorganisms (including $S$. aureus, $S$. epidermidis, $P$. aeruginosa, $E$. coli and $C$. Albicans), which documented that seed oil of M.oleifera has no antimicrobial activity. The lack of antibacterial activity in $M$. oleifera may be attributed to the absence of important phytochemicals such as tannins, flavonoids, and alkaloids. This active phytochemicals have been reported to confer antibacterial property on medicinal plants (Solomon et al., 2013). Furthermore, garlic oil was observed to be effective against all the tested microorganisms.The efficacy of the oil increased with an increase in concentration. At $100 \%(\mathrm{v} / \mathrm{v})$ concentration, the highest sensitivity was observed in Staphylococcus aureus $(11 \mathrm{~mm})$, Escherichia coli $(12 \mathrm{~mm})$, Salmonella Sp. (11 mm), and Pseudomonas aeruginosa (10 mm). While moderate inhibition was observed at the lowest concentration $20 \%(\mathrm{v} / \mathrm{v})$, in Staphylococcus aureus (07 mm), Escherichia coli (07 mm). Salmonella sp. (00 $\mathrm{mm})$, and Pseudomonas aeruginosa $(00 \mathrm{~mm}$ ) were resistance. The result of this reseach, agreed with the research conducted by Ross et al. (2001), which showed that Garlic oil possesses substantial and broadspectrum antibacterial activity against both grampositive and negative bacteria (including Vibrio metschnikovii, S. aureus and L. Monocytogenes). Also, in agreement with the work carried out by Ali and Blunde (2003), which reported that the antibacterial activity of different extracts (n-hexane, chloroform, acetone, butanol, ethanol and methanol) of Garlic against $E$. coli, $S$. aureus, $S$. epidermidis and $K$. pneumonia. 
In addition, Ross et al. (2001), reported that Garlic oil contains diallylsulfide which contribute significantly to its antimicrobial activity. Also, the antibacterial activity of seed oil of Garlic can be attributed to its phytochemicals content, which are known to play a vital role in the antimicrobial activity of plants. In conclusion, the seeds oil of garlic presented activity against all the microorganisms tested, while seed oil of Moringa oleifera was found to be inactive against the tested organisms. Phytochemical screening shows the presence of alkaloids, tannins and saponins in seeds oil of garlic,while only saponin was detected in the seeds oil of Moringa oleifera.

\section{REFERENCES}

Ahmed, I., Mehmood, J., and Mohammad, F.(1998). Screening of some Indian medicinal Plants for their antimicrobial properties. Journal of Ethnopharmacol.62: Pp183-193.

Ali and Blunden (2003). Revealed antibacterial effect of different extracts (n-haxane, chloroform, acetone, butanol, ethanol, and methanol) of garlic sample against $E$. coli, $S$. sureus, $P$. aeruginosa, $S$. epidermidis and $K$. pneumoniae.

Amagase, H. (2006). Clarifying the real bioactive constituents of garlic. Journal of Nutrition.136: 716-725.

Anwar F., Ashraf, M., and Bhanger, M.I.(2005). Interprovenance variation in the composition of Moringa oleifera oil seeds from Pakistan. Journal of American Oil Chem Soc82: 45-51.

Anwar, F., and Bhanger, M.I.(2003). Analytical characterization of Moringa oleifera seed oil grown in temperate regions of Pakistan. Journal of Agricultureand Food Chemistry51: 6558-6563.

Ayaz, E, and Alpsoy, H.C. (2007). Garlic (Allium sativum) and traditional medicine. Actaparasitol. Turcica. 31 (2): 145-149.

Bakri, I.M, and Douglas, C.W.I. (2005). Inhibitory effect of garlic extract on oral bacteria.Arch.Oral Biology. 50(7): 645-651.

Baytop, T. (1999): The treatment plant in Turkey. Nobel Tip Kitobovi, Istanbul.

Bukar, A., Uba A., and Oyeyi, T.I.(2010). Phytochemical analysis and antimicrobialactivity of parkia biglobosa (Jacq.) Benth. extracts against some foodborne microorganisms. Advances in Experimental Biology (In press).

Cheesbrough, M. (2006). Distinct Laboratory Practice in TropicalCountries. Cambridge University Press. Pp 20-35.

Dillard, C.J., German., and J.B.(2000). Phytochemicals: nutraceuticals and human health: A review. Journal of Science of Food and Agriculture80: 1744-1756.

\section{CONCLUSION}

The results of this study have shown the potentials of seed oil of garlic as sanitizers/preservatives. This is due to the fact that it was found to possess antimicrobial activities against some food-borne microorganisms that are often implicated in the spoilage of foods and food-borne illnesses.

\section{RECOMMENDATION}

On the other hand, seed oil of Moringa oleifera can not be used for the above purpose. This is due to its inability to inhibit the growth of the tested food-borne microorganisms. Further research should be conducted to test the sanitizing and preservative effect of the oils on some foods.

Dubey, N.K., Kumar, R., and Tripathi, P. (2004). Global promotion ofherbal medicine: India's opportunity. Curr. Sci. 86: pp37-41.

Farooq, A., Sajid, L., Muhammad, A. and Anwarul,H.G. (2007): Moringa oleifera: a food plant with multiple medicinal uses. Phytotherapy Research. 21:17-25.

Kingston, W.(2008).Irish contributions to the origins of antibiotics.Irish journal of medical science.177 (2): 87-92.

Kojuri, J., Vosoughi, A.R., and Akrami, M. (2007). Effect of anethum graveolens and garlic on lipid profil in hyperlipidemic patients. Lip. Health Dis. 1 (6): 5.

Nuutila, A.M., Kammiovirta, K., and Caldentey, K.M.O. (2002). Comparison of methhods for The hydrolysis of flavonoids and phenolic acid from onion and spinach for HPLC analysis. Journal of Food Chemistry. 76 (4): 519525.

Odebiyi A., and Sofowora, A.E.(1999). Phytochemical screenings of Nigerian medicinal plants parts. Lyodia, 44: pp234-246.

Okigbo, R.N., and Igwe, D.I. (2007). The antimicrobial effects of Piper guineense 'uziza'and Phyllantus amarus 'ebe-benizo' on Candida albicans and Streptococcus faecalis. Journal of Immunology and Microbiology. 54(4):353-366.

Rose, P., Whiteman M., Moore, P.K., and Zhu, Y.Z. (2005). Bioactive 5-alk (en) ylcysteine sulfoxide metabolites in the genus Alliums; the chemistry of potential therapeutic agent. National. Pro. Rep. 22: 351-368

Ross, Z.M., E.A.O, Gara., D.J, Hill., H.V, Sleightholme, and D.J, Maslin (2001). Antimicrobial properties of Garlic oil against Human Enteric bacteria; Evaluation of methadologies and comparison with Garlic oil sulphide and Garlic powder. Applied Environmental Microbiology.67 (1): 475480.

Rossell, J.B.(1991). Vegetable oil and fats. In Analysis of Oil seeds, Fats and Fatty Foods. Elsevier Applied Science: New York, 261-319.

Siddhuraju, P., and Becker, K.(2003). Antioxidant properties of various solvent extracts of 
Bajopas Volume 8 Number 2 December, 2015

total phenolic constituents from three different agro-climatic origins of drumstick tree (Moringa oleifera Lam.). Journal of Agriculture and Food Chemistry.15: 21442155.

SolomonCharles, Ugochukwu., Arukwe, Uche., and Onuoba, Ifanyi (2013). Preliminary phtochemical screening of different solvent extracts of stem bark and roots of Dennetia tripela G. Baker. Asian Journal of Plant Science and Research,3 (3): pp10-13.

Spiliotis, V., Lalas, S., Gergis, V., and Dourtoglou, V.(1997).Comparison of antimicrobial activity of seeds of different Moringa oleifera varieties. Pharm. Pharmacol. Lett.7: 39-40.

Tahiliani, P., and Kar, A.(2000). Role of Moringa oleifera leaf extract in the regulation of thyroid hormone status in adult male and female rats. Pharmacol Res41: 319-323.

Thilza, I., Sanni, S., Zakari, A., Muhammed, T., and Musa, B.(2010).In vitro antimicrobial of water extract of Moringa oleifera leaf stalk on bacterial normally implicated in eye disease. Academic Arena.2:Pp80-83.

Waller, G.R. and Nowacki, E.K. (1978). Role of alkaloids. Alkaloid Biology and Metabolism in Plants. Plenus Press, New York. pp 249. 
Bajopas Volume 8 Number 2 December, 2015 